\title{
PAISAJES DE LA SAL EN ANDALUCÍA
}

\section{Emilia Román López}

Universidad Politécnica de Madrid. Escuela Técnica Superior de Arquitectura de Madrid.

Director de la tesis: José Fariña Tojo

\section{RESUMEN}

Las salinas generan paisajes de características únicas, tanto por sus valores naturales y medioambientales, como por los valores culturales, patrimoniales, históricos, sociales e identitarios. Las energías y circunstancias naturales aprovechadas en ellas, sol, viento, gravedad y humedad relativa, propician una de las estrategias fundamentales para su funcionamiento: la evaporación, que hace determinante su posición geográfica en el territorio y su dependencia de los ciclos climáticos estacionales, del régimen hidrológico, la estructura geológica del subsuelo, la geomorfología y la acción del hombre para potenciar la eficiencia de los procesos productivos.

Actualmente se encuentran, en su mayoría, abandonadas y en estado de ruina, olvidando la importancia cultural, histórica y económica que tuvieron en épocas pasadas. Estos hechos manifiestan la urgencia de la apreciación y el reconocimiento de estos entornos culturales como patrimonio común y de aprovechamiento social inmediato y de que sean objeto de una gestión específica para evitar su desaparición.

Palabras clave: paisaje cultural, territorio, patrimonio, medio ambiente. 
ID_INVESTIGACIONES

\begin{abstract}
Salt works create unique landscapes with both natural and environmental values, due to their cultural, historical and social background, as well as their heritage and identity. The energy and natural circumstances: sun, wind, gravity and relative humidity, facilitate an essential strategy for their operation: evaporation, which emphasizes as decisive their geographical location in the territory and their dependence on seasonal weather cycles, hydrological regime, geological underground structure, geomorphology and human action to enhance the efficiency of production processes.

Nowadays they are mostly abandoned and in ruins, leaving the cultural, historical and economic significance, they used to have in the past, forgotten. These facts show the urgent procedure for the appreciation and recognition of these cultural surroundings as a common heritage of immediate social use, so that they become subject to specific management in order to prevent its disappearance.
\end{abstract}

Key words: cultural landscape, territory, heritage, environment. 

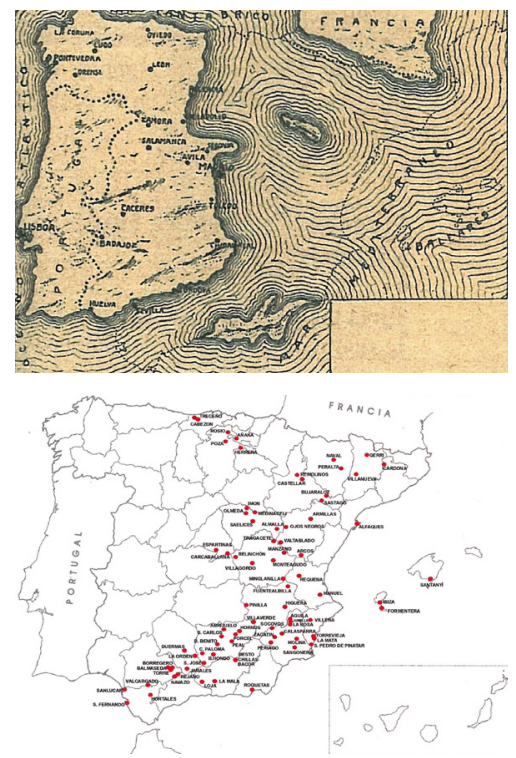

Arriba: Mar de Thetys, hace 200 millones de años (Hueso \& Carrasco, 2008). Abajo: Distribución de salinas a mediados del s. XIX (Plata, 2006).

\section{INTRODUCCIÓN}

Los paisajes de las salinas "son el resultado de la acción e interacción de factores naturales y humanos en el territorio" (CEP, 2000). Se trata de lugares de características únicas, tanto por la biodiversidad asociada a ellos como por la arquitectura, el paisaje singular que generan y su valor ambiental, cultural, patrimonial, histórico, social y su marcada identidad.

Tanto su ubicación en la península ibérica, como los sistemas constructivos y productivos empleados, dependen de factores relacionados con su adaptación al medio ambiente: las condiciones climáticas, el régimen hidrológico de la zona, la geomorfología, la estructura geológica del subsuelo y la acción del hombre para potenciar la eficiencia de los procesos productivos.

Las energías y circunstancias naturales aprovechadas en ellas, sol, viento, gravedad y humedad relativa, propician una de las estrategias fundamentales para su funcionamiento: la evaporación, que hace determinante su posición geográfica en el territorio y su dependencia de los ciclos climáticos estacionales.

\section{OBJETIVOS E HIPÓTESIS}

Actualmente existen trabajos y estudios referentes a los sistemas productivos y constructivos de las salinas, a sus valores naturales y a la biodiversidad asociada a ellas, a temas relacionados con la arqueología, historia, lingüística, etc., pero todavía queda un campo extenso por investigar, objetivo principal de esta tesis, fundamental para el entendimiento y mantenimiento de estos paisajes, como son las interrelaciones que estas explotaciones establecen con su entorno próximo, con los núcleos de población y sus habitantes, la red de carreteras y caminos que las conectan y los cursos fluviales que las sirven.

Para ello se plantean unos objetivos específicos:

- Comprender el paisaje salinero a través del análisis de sus principales características, identificando, clasificando y comparando las distintas tipologías.

- Estudiar su generación y dinámicas de evolución, así como los cambios producidos en estos paisajes, determinando las relaciones causa-efecto. 


\section{ID_INVESTIGACIONES}

- Encontrar las causas del deterioro y desaparición del patrimonio salinero.

- Evaluar la efectividad de las iniciativas, públicas y/o privadas, y de las figuras normativas existentes encaminadas hacia la protección y gestión de estos paisajes.

- Detectar y estudiar las relaciones entre salinas, con su entorno físico inmediato y con el ámbito de escala territorial.

Las hipótesis de la investigación son las siguientes:

a) Las figuras, programas y planes de protección, en los diferentes ámbitos, y las actuaciones puntuales de rehabilitación, gestión y reactivación de las salinas no detienen el progresivo deterioro y desaparición generalizada de estos paisajes.

b) Existe una estructura territorial salinera, en la que se puede determinar, para cada explotación de sal, sus correspondientes ámbitos geográfico-salineros. Una red compleja que, en parte, estructura la actividad del proceso salinero y que, inversamente, sin las salinas no hubiera siquiera existido, y que son parte y trama básica de estos paisajes singulares y específicos.

c) La puesta en valor y gestión inteligente de esta red territorial salinera puede ser una alternativa viable para la reactivación y recuperación global de su patrimonio natural-cultural.

\section{METODOLOGÍA}

Para realizar esta investigación se ha elegido la metodología del estudio de caso múltiple, método cualitativo que ha servido para observar, describir, explicar y evaluar la realidad salinera. Mediante la observación directa, el análisis de textos, imágenes, documentos, gráficos, dibujos, palabras y entrevistas abiertas se ha establecido y comprendido el conjunto de características interrelacionadas que configuran el paisaje salinero.

Los criterios para la elección de los casos de estudio se han basado en los siguientes condicionantes generales:

- Que cubran todo el territorio andaluz 
- Que tengan límites concretos y constituyan unidades autónomas

- Que representen la realidad existente respecto a las variables tipológicas y las relativas a la actividad y estado de conservación del patrimonio salinero.

Mediante el muestreo intencional o de conveniencia la selección de ejemplos representa adecuadamente la situación investigadora que se persigue. Para el estudio de casos se han elaborado dos tipos de fichas; la primera es la ficha de viaje y localización, cuya única finalidad es facilitar la búsqueda y acceso a la salina. La segunda es la ficha de caracterización, donde se realiza una amplia descripción de la explotación mediante la recogida de datos, la observación directa y las entrevistas abiertas. La toma de datos se ha realizado desde la escala territorial hasta la escala de detalle de edificios y sistemas constructivos, para poder establecer un análisis a distintos niveles espaciales.

El trabajo de campo se ha realizado a lo largo de varios años, recorriéndose más de 10.000 kilómetros a través del territorio interior y costero andaluz. Las visitas se han realizado principalmente en "época de cosecha", es decir, en los meses más calurosos (de mayo a septiembre). Este hecho ha posibilitado ver las salinas en plena actividad y poder realizar entrevistas abiertas a multitud de salineros cuya información, no encontrada en documentos escritos, ha sido muy valiosa para realizar esta investigación. En algunas ocasiones también se han realizado visitas en los meses más fríos, cuando la producción salinera se encontraba parada, ya que se ha considerado muy interesante poder observar y documentar las variaciones del paisaje salinero en estas circunstancias.

Los parámetros considerados para escoger los casos de estudio han sido los siguientes:

- Según ubicación geográfica de las salinas. Se ha elegido una muestra que recoja ejemplos de todas las provincias de la Comunidad Autónoma Andaluza: Almería, Cádiz, Córdoba, Granada, Huelva, Jaén, Málaga y Sevilla.

- Según ubicación del recurso. Se han seleccionado dos tipos: salina de manantial (o de interior) y salina costera (o marítima). En algunas provincias andaluzas, debido a su posición geográfica interior en la península no existen salinas marítimas, como en Sevilla, Jaén y 
Córdoba. Sin embargo, en la provincia de Málaga, a pesar de que parte de su territorio es costero, no se han encontrado salinas marítimas. En Almería y Huelva tampoco se han encontrado salinas interiores.

- Según su estado de actividad: activa o inactiva (independientemente de su estado de conservación: abandonada, arruinada o desparecida).

- Según método de obtención. Esta investigación se centra en la obtención de sal por medio de la evaporación solar. Por tanto, quedan fuera las explotaciones de minería, ígneas, vacuum, etc.

- Según la escala del proceso de obtención: artesanal/tradicional e industrial o semiindustrial (cuyo origen fue artesanal/tradicional).

A través de la combinatoria de los parámetros anteriores se obtiene el siguiente cuadro de selección de casos:

\begin{tabular}{|c|c|c|c|c|c|c|c|c|c|}
\hline \multirow{2}{*}{\multicolumn{2}{|c|}{$\begin{array}{l}\text { Parámetros de } \\
\text { selección }\end{array}$}} & \multicolumn{8}{|c|}{ Provincias andaluzas } \\
\hline & & Almería & Cádiz & Córdoba & Granada & Huelva & Jaén & Málaga & Sevilla \\
\hline \multicolumn{2}{|c|}{ Ubicación geográfica } & $x$ & $x$ & $\mathrm{x}$ & $\mathrm{x}$ & $x$ & $x$ & $\mathrm{x}$ & $\mathrm{x}$ \\
\hline \multirow{2}{*}{$\begin{array}{c}\text { Ubicación } \\
\text { recurso }\end{array}$} & Interior & & $\mathrm{x}$ & $\mathrm{x}$ & $\mathrm{x}$ & & $\mathrm{x}$ & $\mathrm{x}$ & $\mathrm{x}$ \\
\hline & Marítima & $x$ & $\mathrm{x}$ & & $\mathrm{x}$ & $\mathrm{x}$ & & & \\
\hline \multirow{2}{*}{$\begin{array}{c}\text { Estado } \\
\text { actividad }\end{array}$} & Activa & $x$ & $\mathrm{x}$ & $\mathrm{x}$ & $\mathrm{x}$ & $\mathrm{x}$ & $\mathrm{x}$ & $\mathrm{x}$ & $\mathrm{x}$ \\
\hline & Inactiva & $\mathrm{x}$ & $\mathrm{x}$ & $\mathrm{x}$ & $\mathrm{x}$ & $\mathrm{x}$ & $\mathrm{x}$ & $\mathrm{x}$ & $\mathrm{x}$ \\
\hline $\begin{array}{c}\text { Método } \\
\text { obtención }\end{array}$ & $\begin{array}{c}\text { Evaporación } \\
\text { solar }\end{array}$ & $x$ & $x$ & $x$ & $x$ & $x$ & $x$ & $x$ & $x$ \\
\hline \multirow{2}{*}{$\begin{array}{l}\text { Proceso } \\
\text { obtención }\end{array}$} & Artesanal & $\mathrm{x}$ & $\mathrm{x}$ & $\mathrm{x}$ & $\mathrm{x}$ & $\mathrm{x}$ & $\mathrm{x}$ & $\mathrm{x}$ & $\mathrm{x}$ \\
\hline & $\begin{array}{c}\text { Semi- } \\
\text { industrial }\end{array}$ & $\mathrm{x}$ & $x$ & $\mathrm{x}$ & $\mathrm{x}$ & $\mathrm{x}$ & $\mathrm{x}$ & $\mathrm{x}$ & $x$ \\
\hline
\end{tabular}

La selección y análisis de los casos de estudio ha perseguido los siguientes objetivos:

a) Describir las características de interés para el objeto de esta tesis.

b) Establecer comparaciones entre casos o entre variables definitorias de dichos casos.

c) Identificar la asociación o correlación entre casos o variables.

d) Identificar relaciones causa-efecto.

El número de ejemplos seleccionados se ha establecido de tal manera que, como mínimo, cubra el $20 \%$ del total de salinas existentes en cada provincia. En muchas ocasiones, debido al plan de visitas, a la accesibilidad y/o cercanía de las salinas en una zona, al número total existente en cada provincia (que en ocasiones era reducido) o en función del
Combinatoria y parámetros para selección de casos de estudio. Elaboración propia. 
tiempo destinado a cada viaje, se ha superado ampliamente el mínimo establecido.

\begin{tabular}{|c|c|c|c|c|c|c|c|c|c|}
\hline & \multicolumn{10}{|c|}{ Provincias andaluzas } \\
\hline & Almeria & Cádiz & Córdoba & Granada & Huelva & Jaén & Málaga & Sevilla & Total \\
\hline Total salinas & 5 & 81 & 22 & 6 & 22 & 34 & 4 & 12 & $\mathbf{1 8 6}$ \\
\hline Casos estudio & 5 & 19 & 15 & 4 & 9 & 13 & 2 & 6 & $\mathbf{7 3}$ \\
\hline Porcentaje casos & $100 \%$ & $23 \%$ & $75 \%$ & $66 \%$ & $45 \%$ & $40 \%$ & $50 \%$ & $50 \%$ & $39 \%$ \\
\hline
\end{tabular}

Realizada la selección de los casos de estudio, y previo a las visitas de campo, se procedió a su localización y georreferenciación mediante Sistemas de Información Geográfica, a través de datos e indicaciones encontradas en diferentes publicaciones, textos antiguos y también mediante la toponimia del territorio, que ha facilitado en gran medida la ubicación de las explotaciones, ya que en un alto porcentaje las salinas se encontraban junto a elementos naturales y/o antrópicos que hacían referencia a la sal: arroyo salado, cerro de la sal, arroyo de la saladilla, casa del salinero, cortijo de las salinas, etc.

Una vez localizada la salina se completa la ficha de viaje y localización, que contiene datos muy básicos, destinados a facilitar el trabajo de campo. Las fichas se han cumplimentado antes de realizar los viajes a cada provincia, para poder estimar su duración, el programa de visitas y la posibilidad de realizar entrevistas. Los datos y la estructura de esta ficha es la siguiente:

a) Nombre de la salina

b) Situación: Municipio y provincia

c) Localización geográfica: latitud, longitud, Coordenadas UTM (huso UTM: 30)/Datum ETRS89.

d) Plano de situación: imagen extraída del Mapa Provincial (1:200.000)

e) Plano de localización: imagen extraída del Mapa Topográfico Nacional (1:25.000)

f) Fotografía aérea: Imágenes extraídas de ortografías de vuelos recientes realizados para el SIGPAC. A través de la observación de las orto fotos se pudieron apreciar, antes de la visita, las modificaciones más recientes que habían sufrido las salinas. Incluso en algunas ocasiones se ha detectado la total eliminación de la explotación salinera. Por ejemplo, es el caso de la desaparición de Salinas de Terreros, en Pulpí (Almería) o el de las salinas en 

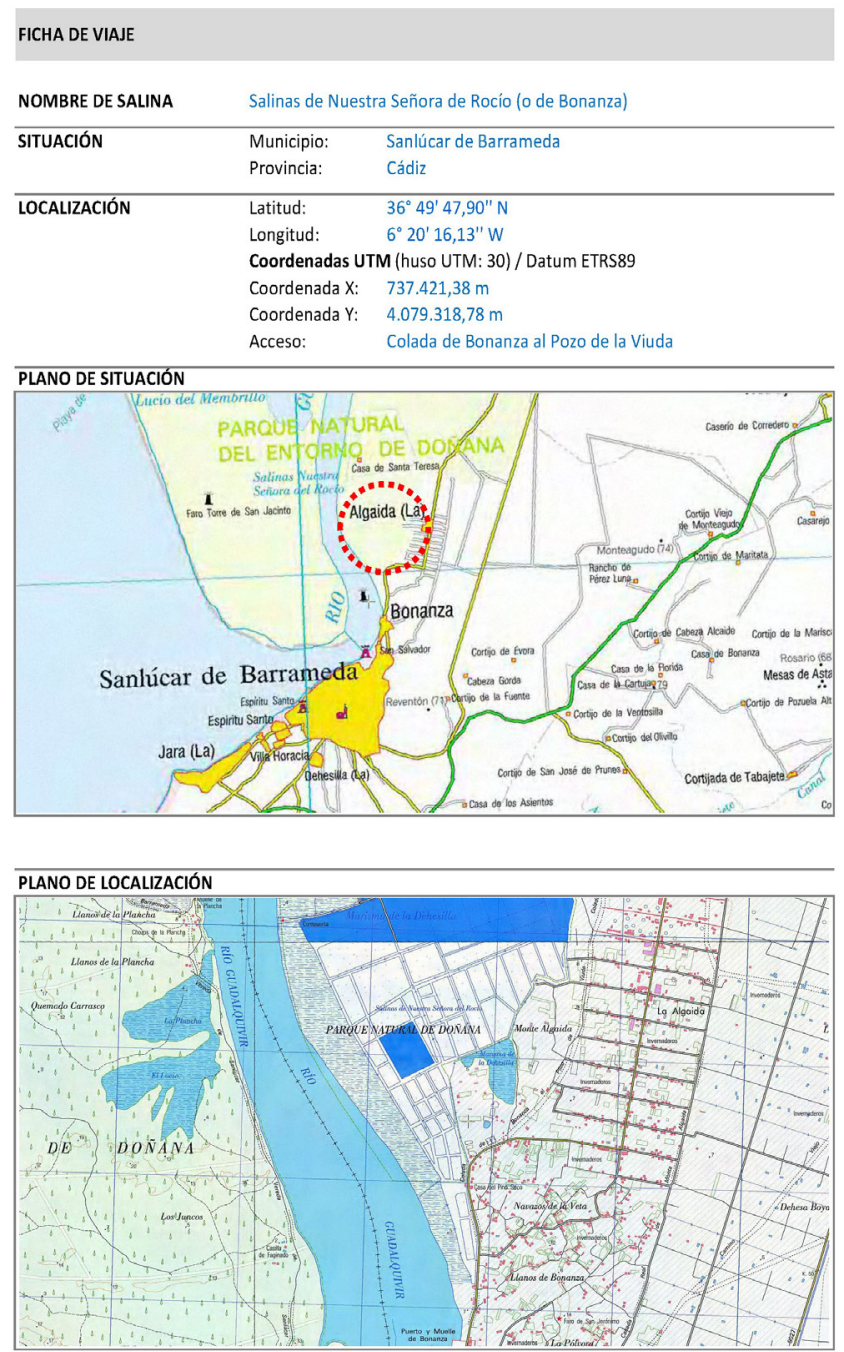
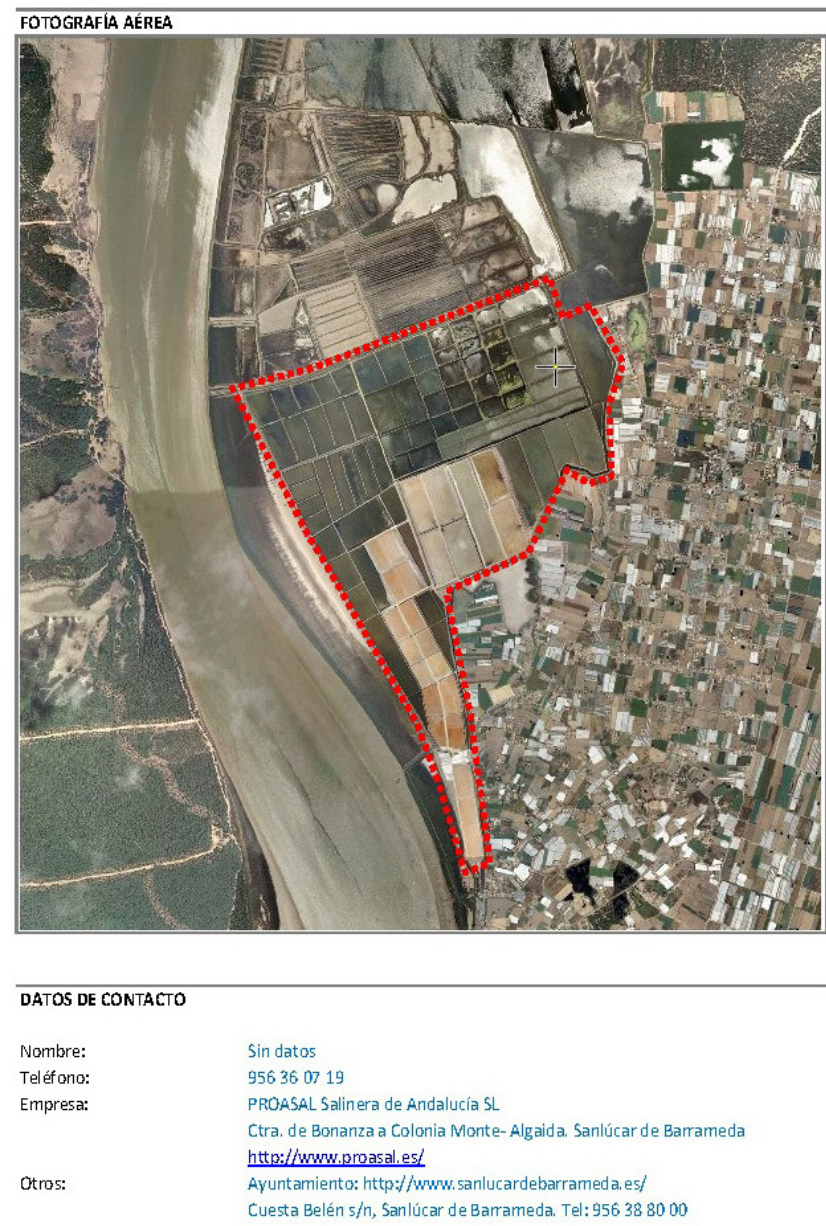

\section{NOTAS}

Por su extensión y las grandes dimensiones de las balsas evaporadoras o cristalizadores, estas salinas se pasado de ser salinas artesanales a salinas industriales. Parece que actualmente siguen activas. Comprobar in situ. 


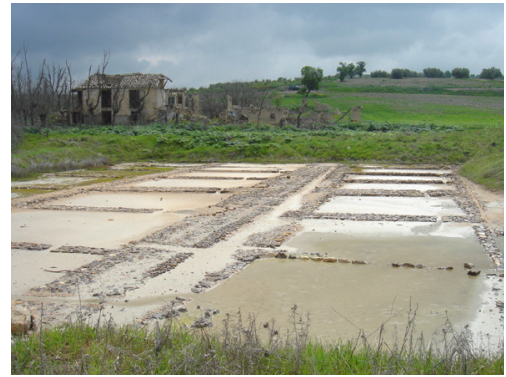

Edificios y eras en Salinas de Calderón, Cazorla (Jaén). Fotografía de la autora. la desembocadura del río Guadiaro, en San Roque (Cádiz). Esta última debida, entre otras cosas, a la construcción de la urbanización y campo de golf de "Sotogrande".

g) Datos de contacto: relativos al nombre de la empresa y/o las personas relacionadas con la explotación (propietarios, trabajadores, etc.), como teléfono, email, web, etc. En el apartado "otros", se indican, generalmente, datos del ayuntamiento del municipio donde se halla la salina, ya que en ocasiones ha facilitado información valiosa para la investigación. Esta situación no era la habitual, pues las salinas pertenecen en su mayoría a propietarios particulares, que son los que disponen de la información más abundante y valiosa (fotografías antiguas y recientes, planos, documentos escritos, información oral, etc.)

h) Notas: donde aparecen datos a destacar, llamadas de atención y avisos a tener en cuenta durante la visita de campo.

A modo de ejemplo se muestra, en la página de la izquierda, la ficha de viaje de Salinas de Nuestra Señora del Rocío (o de Bonanza), ubicadas en Sanlúcar de Barrameda (Cádiz).

\section{LA SALINA ARTESANAL, UN PROCESO PREINDUSTRIAL SOSTENIBLE}

La ecología industrial trata de entender los procesos industriales en relación con el medio natural, para intentar reducir los impactos que éstos producen sobre la naturaleza. Una salina artesanal es un buen ejemplo en este sentido, ya que se asemeja bastante a un ecosistema natural, con tendencia a cerrar el ciclo de materia y a hacer eficientes los procesos internos, obteniendo un nivel prácticamente cero en la generación de residuos. La actividad salinera transforma un medio rural-natural en un medio preindustrial-artesanal donde, mediante la utilización de energías renovables, se produce la transformación del agua salada en salmuera o sal.

En el proceso de producción artesanal de sal se pueden distinguir las siguientes fases:

a) Fase inicial: Localización y construcción. Localización y construcción de la salina, proceso ligado totalmente a las condiciones del medio físico pues, como se ha mencionado anteriormente, sin unas características determinadas del territorio no se puede obtener la materia prima que inicia el ciclo: el agua salada.

b) Fase de explotación: producción-almacenamiento-transporte-venta. Transformación del 
agua salada en salmuera o sal, para lo que se requiere la existencia y combinación de determinadas condiciones climáticas determinadas por la radiación solar, la ventilación, la humedad y la temperatura. A este proceso de adaptación climática se une el hombre a través del diseño de la instalación salinera, con la construcción de eras de evaporación, norias, calentadores, concentradores, canalizaciones, etc., para potenciar los efectos de las condiciones naturales. Tras la evaporación del agua excedente se obtiene la sal o salmuera.

Almacenamiento de la sal en los alfolíes, para terminar el proceso de secado, mantener limpia y proteger la sal de las inclemencias del tiempo.

Transporte del producto final desde los almacenes hasta los núcleos urbanos, a través de la red de caminos y carreteras, en los que se encuentran los puntos de venta y distribución. En algunas ocasiones el transporte de la sal o salmuera se realiza directamente desde los almacenes hasta el punto de consumo directo (por ejemplo, en la elaboración de aceitunas para consumo, el mantenimiento de carreteras, etc.).

Pero tradicionalmente algunos almacenes y los toldos, o puntos de venta, de cada salina se ubicaban en las ciudades y pueblos cercanos, de tal manera que existía un ámbito territorial para cada salina llamado Partido. Es decir, que cada explotación de sal abastecía de este producto a determinados habitantes, pues existía "un reparto de áreas territoriales donde era obligatorio y exclusivo el consumo de sal de determinada salina. Así se aseguraba la venta de cada producción y se atemperaba ésta, y los precios de arrendamiento de la salina, a las necesidades de consumo de la zona asignada" (Porres, 2003:63). De hecho, históricamente existieron multitud de disputas en toda la Península Ibérica por los límites de las demarcaciones salineras y sus mercados. Un claro ejemplo fueron las eternas batallas y pleitos entre las Salinas de Añana (Álava) y las Salinas de Poza de la Sal (Burgos) por el abastecimiento de sal del Partido de Castilla la Vieja y Zamora.

c) Fase final: reinserción-integración. Durante la última fase del ciclo de vida de una salina artesanal, cuando el proceso de explotación llega a su fin y se abandona la explotación salinera se produce, en muchos casos, la reinserción e integración casi total de estas estructuras en los ciclos naturales y en el paisaje rural o natural en el que se ubican.

A veces es difícil distinguir qué zona fue modificada por el hombre y qué parte es obra de la propia naturaleza. Si se observa con atención, se pueden distinguir entre la vegetación

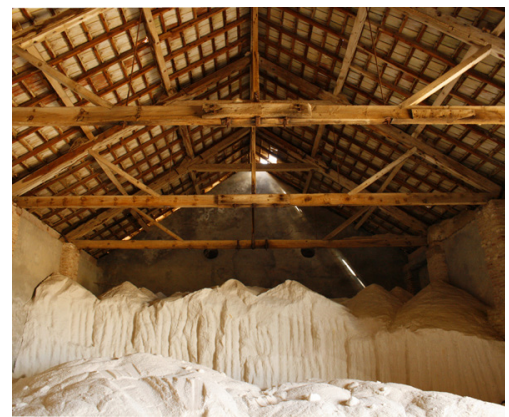

Almacén de Salinas de Fuente Camacho, Loja (Granada). Fotografía de la autora.

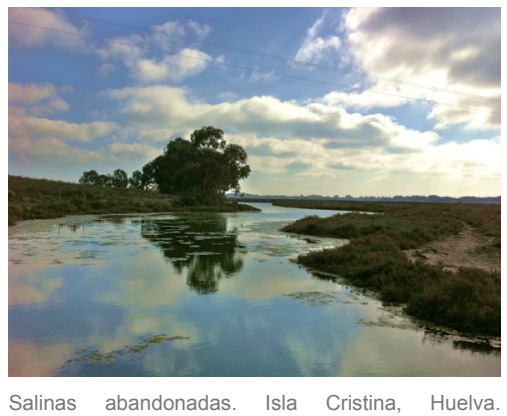
Fotografía de la autora. 
y el agua salada leves huellas del trazado original de las balsas o eras de evaporación, concentradores, calentadores, etc. de la explotación salinera.

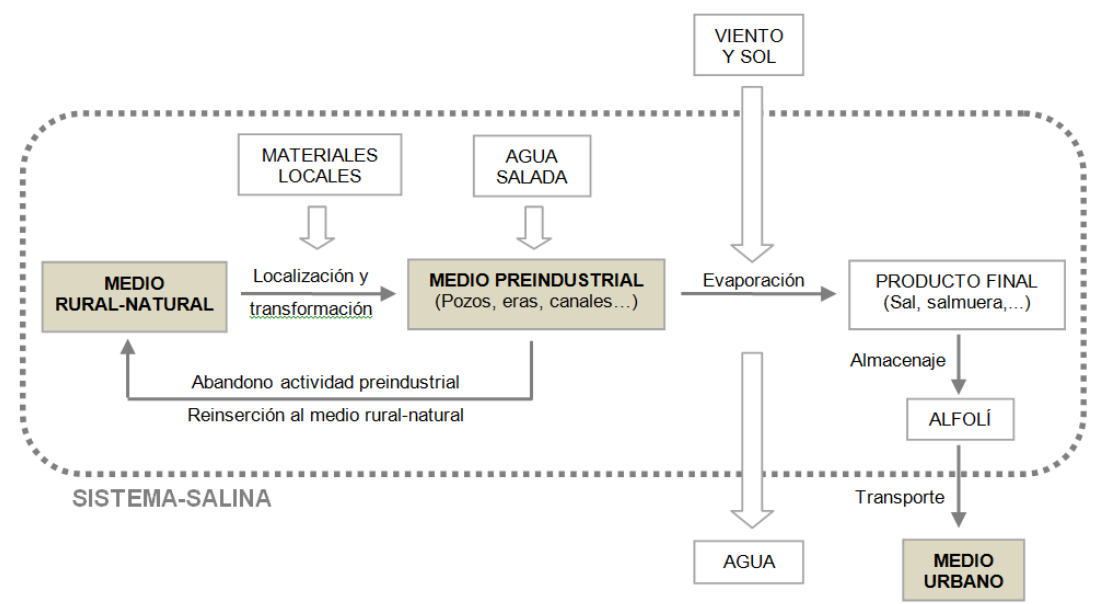

\section{EL PAISAJE CULTURAL SALINERO}

\subsection{La toponimia como medio de significación de las salinas en el territorio}

Según La Real Academia de la Lengua, la toponimia viene del griego (то́тоৎ-topos: lugar, y övoua-onoma: nombre) y se define como "El estudio del origen y significación de los nombres propios de lugar. Conjunto de los nombres propios de lugar de un país o de una región."

El lenguaje, como medio a través del cual el hombre expresa lo que piensa y lo que siente, no es una realidad aislada, sino que depende en gran parte de su contexto. Por ello, está relacionado intrínsecamente con el entorno en el que se desarrolla, tanto sociocultural, histórico como el relacionado con el medio físico y territorial. Este hecho viene manifestado por varios autores:

"Cuantas realidades ofrezcan una peculiaridad regional deben recogerse con sus nombres" (García de Diego, 1951:11-14) 
"En este sentido, no debemos olvidar que la lengua, en definitiva, está al servicio de la comunidad y es el medio de expresión idóneo, el instrumento más eficaz con que cuenta ésta para dar a conocer su tradición cultural y su idiosincrasia; al tiempo que el continuo proceso de transformación sociocultural se verá reflejado en ella mediante su propio proceso transformador y creador" (Prado, 1992:18)

El lenguaje es parte de la herencia cultural de toda sociedad y, por tanto, el estudio de la toponimia salinera ha sido muy interesante para el conocimiento y comprensión de estos lugares, ya que las salinas y los paisajes asociados a ellas son de inestimable valor histórico, cultural y, en ocasiones, pilar elemental de la identidad local de sus pobladores, como por ejemplo las Salinas de San Fernando, en Cádiz.

Mediante la toponimia los pobladores y, en especial, los salineros de Andalucía, con estrecha vinculación a estos paisajes, han identificado y designado a lo largo de los años lugares y elementos de su entorno, tanto naturales (ríos, arroyos, fuentes, barrancos, cerros, lomas, valles, etc.), como también antrópicos (poblaciones, construcciones, salinas, huertos, etc.).

De esta manera aparecen en las distintas provincias andaluzas multitud de nombres con referencias a la sal: Arroyo Salado, Arroyo de la Salinilla, Casa de la Salina, Cortijo del Salado, Cerro de las Salinas, Barranco del Saladero, Rambla de la Saladilla, etc.
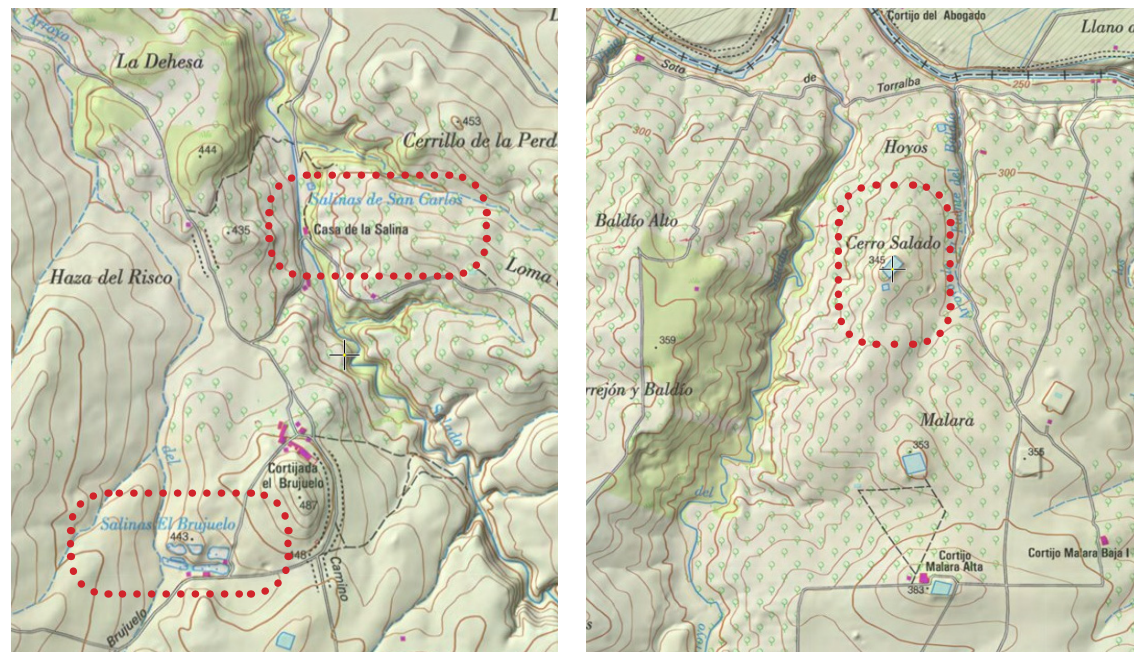

Izquierda: Salinas de El Brujuelo, de San Carlos y Casa de la Salina, junto al Arroyo del Salado en la provincia de Jaén. Derecha: Cerro Salado, en la provincia de Jaén. Elaboración propia a partir del MTN25. 
En los gráficos siguientes se puede comprobar este hecho, al observar y analizar, mediante el mapa topográfico, la ubicación de las Salinas de El Brujuelo, las Salinas de San Carlos y la Casa de la Salina junto al Arroyo del Salado, en la provincia de Jaén. Si nos trasladamos, siguiendo el curso del mismo arroyo, unos siete kilómetros hacia el norte de esta ubicación podemos encontrar el Cerro Salado. Todos ellos son topónimos salineros referentes al medio físico natural (cursos fluviales y elementos del relieve) y al medio antropizado (construcciones rurales).

En la búsqueda y análisis de topónimos salineros en los diversos municipios de Andalucía se han encontrado, en total, 708 nombres relacionados con la sal, que se refieren a elementos naturales, principalmente a cursos fluviales y a lugares/parajes. Respecto al medio antrópico también se han encontrado numerosas referencias a edificaciones rurales, poblaciones, obras hidráulicas, vías de comunicación y lugares relacionados con la explotación de la sal.

En el cuadro resumen se puede comprobar que los topónimos más abundantes en la Comunidad Autónoma Andaluza son los relativos a explotaciones salineras (198), seguidos por los referentes a edificaciones rurales (137), cursos fluviales (132) y a lugares/parajes naturales (118). Los menos abundantes son los referentes a obras hidráulicas (6). Sin embargo, existen más nombres relacionados con el medio antropizado (387) que con el medio natural (321).

Las provincias que más topónimos relacionados con la sal tienen son las provincias de Cádiz (156) y la de Jaén (147), seguidas por las de Córdoba (95) y Sevilla (86), mientras que las que menos topónimos salineros tienen son la provincia de Huelva (49) y la de Málaga (52). Esta circunstancia se puede relacionar directamente con el número de salinas existentes en dichas provincias, ya que Cádiz es la provincia que más salinas tiene (97), seguida por Jaén (34). Sin embargo Málaga es una de las que tienen menos (4), junto a Granada (4).

Jaén es la provincia que tiene más topónimos salinos relacionados con la hidrología (33), las construcciones rurales (36) y los lugares/parajes naturales (25). Sin embargo Cádiz es la que tiene más topónimos referentes a lugares de explotación salinera (97), a las vías de comunicación (6) y a los elementos del relieve (11). 


\begin{tabular}{|c|c|c|c|c|c|c|c|c|c|c|c|c|c|}
\hline \multirow{3}{*}{ Provincia } & \multicolumn{7}{|c|}{ MEDIO NATURAL } & \multicolumn{5}{|c|}{ MEDIO ANTRÓPICO } & \multirow{3}{*}{ Total } \\
\hline & \multicolumn{2}{|c|}{ Hidrología } & \multicolumn{4}{|c|}{ Geomorfología } & \multirow{2}{*}{$\begin{array}{l}\text { Lugar/ } \\
\text { Paraje }\end{array}$} & \multicolumn{2}{|c|}{ Edificaciones } & \multirow{2}{*}{$\begin{array}{c}\text { Vías } \\
\text { Comunic. }\end{array}$} & \multirow{2}{*}{$\begin{array}{c}\text { Obra } \\
\text { Hidráulic. }\end{array}$} & \multirow{2}{*}{$\begin{array}{l}\text { Actividad } \\
\text { salinera }\end{array}$} & \\
\hline & MA & CF & EV & D & LL & RL & & PM & E & & & & \\
\hline Almería & 3 & 11 & 4 & 3 & 2 & - & 14 & 1 & 11 & 1 & - & 5 & 55 \\
\hline Cádiz & 2 & 21 & 7 & 2 & 1 & 1 & 6 & 4 & 9 & 6 & - & 97 & 156 \\
\hline Córdoba & - & 16 & 2 & - & 1 & - & 24 & 2 & 24 & 5 & - & 21 & 95 \\
\hline Granada & - & 17 & 6 & 1 & 2 & 1 & 15 & 4 & 12 & 4 & 2 & 4 & 68 \\
\hline Huelva & 4 & 10 & 1 & 1 & - & 1 & 4 & - & 7 & - & - & 21 & 49 \\
\hline Jaén & - & 33 & 7 & 1 & 2 & - & 25 & 4 & 36 & 5 & - & 34 & 147 \\
\hline Málaga & 1 & 10 & 4 & - & 1 & 2 & 12 & 5 & 12 & 2 & - & 4 & 52 \\
\hline Sevilla & 3 & 14 & 2 & 2 & - & 1 & 18 & 2 & 27 & 1 & 4 & 12 & 86 \\
\hline TOTAL & 13 & 132 & 33 & 10 & 9 & 6 & 118 & 22 & 137 & 24 & 6 & 198 & 708 \\
\hline \multicolumn{14}{|l|}{ Leyenda: } \\
\hline \multicolumn{4}{|c|}{ MA: Masa de Agua } & \multicolumn{4}{|c|}{ D: Depresión } & \multicolumn{6}{|c|}{ PM: Población / municipio } \\
\hline \multicolumn{4}{|c|}{ CF: Curso Fluvial / Fuente/Pozo } & \multicolumn{4}{|c|}{ LL: Llanura } & \multicolumn{6}{|c|}{ E: Edificación rural } \\
\hline EV: Elevación & & & & $\mathrm{RL}$ & Relie & litora & marítimo & & & & & & \\
\hline
\end{tabular}

Topónimos relacionados con la sal en Andalucía. Elaboración propia.

\subsection{La construcción del paisaje de la sal}

Para la comprensión de los paisajes culturales salineros se deben considerar tres conceptos fundamentales, generadores de estos lugares, y sus interrelaciones:

a) Los procesos e infraestructuras realizadas por el ser humano para la obtención y distribución de la sal, que mantienen una estrecha vinculación con el territorio como basesoporte de dicha actividad. Lo que ha sido denominado por algunos autores con el término de "agricultura mineral"1.

b) El territorio, como soporte físico indisociable al paisaje salinero, su gestión y las características estructurantes del mismo, como son la geología, hidrología, vegetación, relieve, clima, etc. y la articulación territorial, establecida mediante las interconexiones con las redes de caminos y vías, sus jerarquías y las relaciones con los núcleos urbanos.

Como se ha dicho anteriormente, cada salina poseía sus ámbitos territoriales de abastecimiento, que a veces no se encontraban claramente delimitados y eran motivo de disputas entre villas productoras. En algunas épocas de la historia estos ámbitos fueron eliminados para establecer un comercio libre de la sal, como en época de Felipe II, aunque esta decisión también fue causante de grandes tensiones, pues las poblaciones cercanas a salinas se abastecían de ellas, aunque hubiesen pertenecido históricamente a otro Partido

${ }^{1}$ Término utilizado por Pedro Payán Sotomayor (1987), profesor de Lengua Española de la Universidad de Cádiz. 


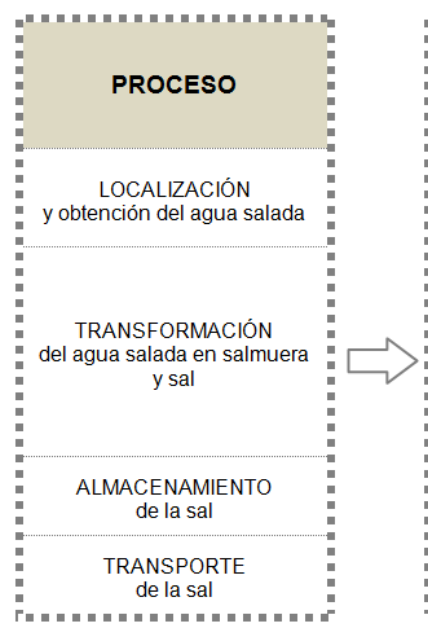

La construcción del paisaje salinero. Elaboración propia. salinero. Es decir, que primaba el criterio de proximidad a la salina y no el político-económico establecido por la Corona.

c) El patrimonio, como herencia cultural propia del pasado de estas estructuras de la sal, que engloba elementos materiales e inmateriales: arquitectura, historia, cultura e identidad social, y que representa la estrecha relación entre el hombre y el medio natural.

\subsection{El patrimonio salinero}

\subsubsection{La arquitectura y los sistemas de producción: el patrimonio construido}

Una de las características del paisaje salinero es su especificidad para cada lugar, debido a su adaptación al medio y a la intervención humana. El tipo de asentamiento en el territorio, la extensión de la explotación y los sistemas constructivos y productivos de las salinas son elegidos y proyectados por el hombre para adaptarse a los diferentes climas y condiciones físicas de cada lugar, de tal manera que el diseño atenúa e incluso invierte las diferencias productivas relacionadas con las variables geológicas o climáticas.

Las salinas parecen estructuras sencillas, pero estos sistemas de producción artesanal encierran cierta complejidad. Como se ha comentado anteriormente, están concebidos para 


\section{ID_INVESTIGACIONES}

hacer llegar el agua salada desde el mar, río, arroyo, etc., hasta las balsas de evaporación a través de canalizaciones y conductos, donde se incrementa lentamente la salinidad del agua (salmuera). Por último se obtiene el producto final mediante la evaporación solar. Una vez obtenida la sal, se almacenará hasta su posterior distribución a los puntos de venta.

Para realizar todo este proceso es fundamental la presencia de los siguientes elementos, construidos con materiales locales como el barro, piedra, madera, arcilla, cal, etc.:

a) Edificaciones. Se pueden diferenciar:

- Las que forman parte del sistema productivo: almacenes o alfolíes, oficinas, molinos, etc. La construcción fundamental e imprescindible es el almacén, existente en todos los casos visitados en un buen estado de conservación, en ruinas o derruido. Sin embargo edificios para oficinas no se han hallado en todas las salinas, quizás es debido a que en estos casos la producción debía ser de carácter familiar, o que éstas se ubicaban en los núcleos urbanos próximos.

- Las necesarias para la vida cotidiana. A pesar de que estas instalaciones salineras no distaban mucho de los núcleos urbanos, en muchas ocasiones, la dificultad de los desplazamientos diarios, debido a la complicada accesibilidad de los terrenos, dio lugar a la construcción de viviendas para los trabajadores junto a las salinas. Esto originó formas de asentamiento autónomo y disperso en el territorio, propio de la arquitectura rural, con construcciones diseminadas cerca de las eras de sal. Por el mismo motivo se construyeron edificios complementarios, propios de la vida cotidiana de la época, como ermitas e iglesias. Por ejemplo, las Salinas de Duernas en Córdoba, que están constituidas por dos almacenes, uno de origen romano, una iglesia, y edificios de oficinas y de viviendas distribuidos en torno a tres patios.

- Las de uso mixto o productivo-vividero, donde se mezclaban los espacios destinados a vivienda con las oficinas y almacenes para la sal. Habitualmente se estratificaban por pisos, en las plantas altas solían estar los espacios domésticos y en las bajas los relacionados con la producción. Un claro ejemplo de e construcción es el edificio de las Salinas de Chíllar, en Hinojares (Jaén)

b) Sistemas de canalización y conducción, a los que se asocian cantidad de construcciones 


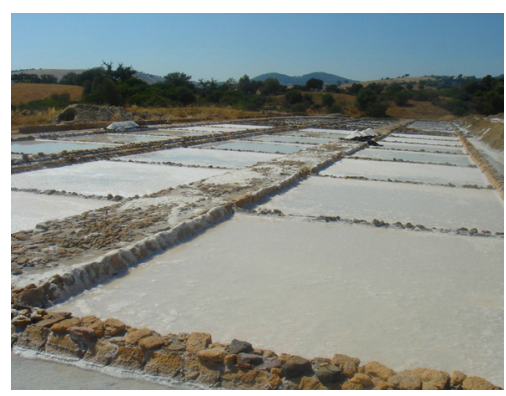

Eras de evaporación en Salinas de Cabeza Hortales, Prado del Rey (Cádiz). Fotografía de la autora. de gran belleza arquitectónica y natural, como son pozos, norias, molinos, compuertas, esteros, vueltas de periquillo, retenidas, etc. Existen diferencias entre las salinas litorales y las de interior:

- En las salinas de interior el sistema de distribución del agua salada se realiza mediante canales o conductos, generalmente de madera o de piedra. El agua se mueve por gravedad desde los calentadores o concentradores hasta las eras, y de unas eras a otras mediante compuertas de madera. En unas ocasiones el agua brota a la superficie a través de manantiales o se recoge directamente del arroyo o río salado, mientras que en otros casos el agua subterránea se extrae mediante norias o molinos que utilizan la fuerza animal, mecánica o eólica (en la actualidad mediante bombas)

- En las salinas del litoral atlántico el agua se recoge en el estero, que se alimenta de agua salada a través del caño, para pasar posteriormente a unos largos canales de ancho entre 3 a $7 \mathrm{~m}$, distribuidos en forma de serpentín, por los que discurre lentamente. Según avanza el agua salada van disminuyendo cada vez su profundidad para conseguir mayor concentración de sal (esteros, vueltas de periquillo, retenidas, etc.). El agua se distribuye de unos sitios a otros mediante compuertas de madera hasta acabar en los cristalizadores, último paso para la obtención de la sal. Sin embargo las salinas del litoral mediterráneo, debido a la falta de mareas ${ }^{2}$, se ubican en las partes más bajas del litoral. La alimentación de agua se produce mediante el uso de molinos de viento, la energía del propio oleaje o mediante estaciones de bombeo eléctricas. Es el caso de Salinas de Cabo de Gata, en Níjar (Almería), donde el 80 \% del agua que recibe procede de bombeo y el resto por oleaje.

c) Superficies de evaporación: constituidas por diversas tipologías como las eras, balsas, concentradores, calentadores, cristalizadores, tajería, etc. Respecto a estos elementos también existen grandes diferencias entre las salinas de interior y las litorales, por ejemplo en el número y tamaño de eras. En las salinas litorales la superficie de evaporación es mucho mayor porque las condiciones para la obtención de sal son peores, debido a la menor concentración en la disolución salina $\left(3-4^{\circ}\right.$ Beaumé $\left.{ }^{3}\right)$. Esto implica que la salina se

${ }^{2}$ No suele haber mareas mayores de $0,5 \mathrm{~m}$.

${ }^{3}$ Un grado Beaumé equivale a una concentración de 11 gramos de sal por litro de agua: $1^{\circ} \mathrm{Be}=11 \mathrm{gr} / \mathrm{l}$ 


\section{ID_INVESTIGACIONES}

distribuye en menor número de eras, pero con mayor superficie. Las salinas de Aragonesas ${ }^{4}$, en Huelva, tienen superficies de evaporación de hasta 450 × 140 metros.

Sin embargo en las salinas de interior la concentración habitual supera los 15-16² Beaumé, llegando a casos extremos como en Salinas de Añana, en Álava, donde la concentración del agua que sale del manantial es de $25^{\circ}$ Beaumé (270 gr/l).

Esto supone que, al tener una concentración de sal superior, no necesita eras tan grandes para obtener igual o mayor producción. También permite que las salinas de interior se adapten muy bien a las condiciones topográficas del lugar, al poder dividirse en multitud de eras de tamaños reducidos (aproximadamente $5 \times 5$ metros), pero de gran productividad.

Otro factor que modifica el hombre mediante técnicas productivas y constructivas es la concentración de sal en el agua. En las salinas de interior el agua salada pasa a los recocederos y concentradores antes de ser esparcidos por las eras, para aumentar la concentración de sal. Sin embargo en las salinas de litoral el aumento de concentración se produce al pasar el agua a través de las diferentes canalizaciones: caño, estero, lucios, retenidas y vueltas de periquillo, hasta llegar a la tajería, donde se encuentran los cristalizadores. Además la profundidad de estas eras es menor en las zonas litorales donde, como se ha comentado anteriormente, la salinidad del agua es menor. Si fuesen muy profundas tardaría mucho tiempo en obtenerse la sal mediante la evaporación y por tanto serían menos rentables.

d) Las redes de comunicación, esenciales para la distribución de la sal a través de carreteras, caminos, cañadas, cordeles, veredas, etc., sin olvidar el transporte marítimo, que llevaba la sal desde las costas hacia zonas interiores que no tenían puntos de abastecimiento próximos (la zona noroeste y oeste de la península) y que antiguamente eran de difícil acceso terrestre debido al mal estado de las vías interiores y a la inseguridad (mediados del siglo XIX). La sal se conducía desde las salinas y alfolíes hasta los toldos, ubicados en los núcleos de población, donde se realizaba la venta al por mayor hasta los puntos de consumo domésticos.

El comercio de la sal propició la comunicación con el extranjero e incluso la construcción

${ }^{4}$ Estas salinas se han reconvertido en su totalidad en salinas industriales. 


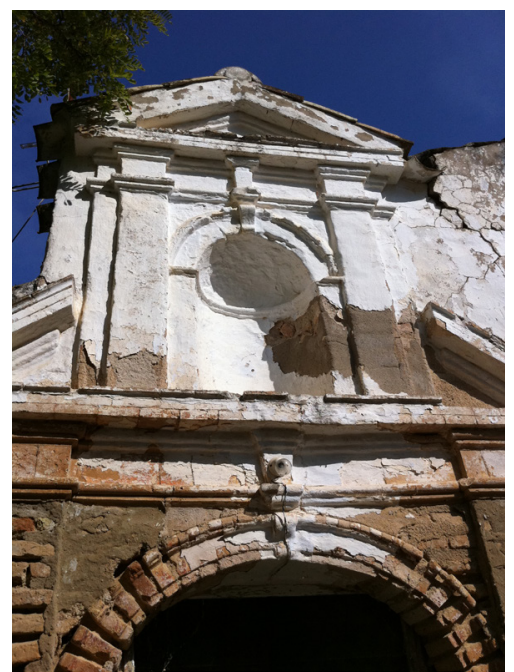

Iglesia de Salinas de Duernas, Córdoba. Fotografía de la autora. de famosas vías de comunicación, como la Vía Salaria que, en época romana, partía de la capital y cruzaba transversalmente la península italiana hacia el Mar Adriático (242 km de longitud).

También el consumo de sal para el ganado, que necesita consumir grandes cantidades de sal al año ${ }^{5}$, estableció una estrecha relación entre vías salineras y vías pecuarias, coincidiendo éstas en muchos casos, y entre salinas y zonas de pastos o de invernada del ganado. De hecho, en Andalucía el acceso a muchas salinas se produce a través de cañadas reales, cordeles, veredas, etc., como el acceso a las Salinas de Valcargado, en Utrera (Sevilla), que se produce por la Cañada Real de Prado Gallego, el acceso a las Salinas de Tejas Coloradas, en Baena (Córdoba) a través del Cordel de Castro del Río a Porcuna, etc.

En definitiva, toda esta red territorial, formada por edificios, eras de evaporación, sistemas de canalización, paisajes, caminos y núcleos de población, es la expresión de los modos de vida y del sistema económico y productivo que la comunidad salinera creó en su momento.

Todas sus construcciones se caracterizan por ser arquitecturas sencillas y funcionales, adaptándose a las necesidades de las familias salineras que las utilizaron y habitaron. En muchas ocasiones podemos observar cierta voluntad estética, encontrando buenos ejemplos de arquitectura doméstica y religiosa.

Desgraciadamente la mayoría de estos edificios se encuentra en un avanzado estado de deterioro, fruto del olvido y del paso del tiempo, mientras que en otros casos han desaparecido en su totalidad por culpa de la especulación inmobiliaria, como es el caso de gran número de salinas existentes en el litoral almeriense. Esta es la lamentable situación actual del patrimonio construido salinero.

\subsubsection{La representación simbólica, identitaria y cultural de los paisajes de la sal}

Las emociones que el ser humano siente al contemplar un paisaje están directamente relacionadas con la sensibilidad, la memoria, el aprendizaje y los fenómenos sociales y culturales que lo rodean. De hecho, el paisaje observado por las personas que lo producen,

${ }^{5}$ La sal se utiliza como complemento vitamínico para estos animales. 
gestionan y viven, en este caso los salineros y vecinos de las salinas, genera emociones y sentimientos distintos que en las personas que lo contemplan por primera vez, como los visitantes o turistas ocasionales.

Este fenómeno es debido a la experiencia que se va adquiriendo del mismo, como bien explicaba el ecólogo F. González Bernáldez (1985) cuando hacía referencia a los entornos naturales desconocidos, aunque también se podría aplicar a los paisajes de la sal: "Los sentimientos que provoca el paisaje y son causa de su aprecio, tienen que ver con un sistema general de emociones, promotor de la supervivencia, facilitador de la explotación y de la orientación en entornos naturales relativamente desconocidos. Tales sentimientos, un día vitales para nuestros antecesores, están hoy reducidos a su inefable y misterioso papel "estético". Sin embargo, a medida que el sujeto interacciona y conoce su entorno a través de su experiencia, este sistema emocional de pre-orientación y consejo pierde vigencia y pasa a segundo plano".

Esta experiencia e interacción entre hombre y paisaje salinero ha sido representada a través de diversas manifestaciones artísticas, como la pintura, la fotografía, la música y la literatura.

Existen numerosos ejemplos de lo anterior y, en la mayoría de casos, los autores son personas con estrecha vinculación emocional con las salinas, como por ejemplo el poeta Rafael Alberti, que nació en el Puerto de Santa María o el cantaor Camarón de la Isla que nació en San Fernando (poblaciones gaditanas con larga tradición salinera). Ambos artistas crecieron y vivieron durante su infancia junto a estos paisajes de la sal y expresaron sus emociones y sentimientos hacia ellos a través de la poesía y el cante ${ }^{6}$.

El paisaje es entendido como la realidad física que observamos y el patrimonio como su representación simbólica, identitaria y cultural. En este sentido también existen numerosos ejemplos de pinturas, fotografías y postales antiguas sobre las salinas, que reflejan muy bien la evolución de estos paisajes y del contexto cultural, histórico y social que ha girado en torno a ellos a lo largo de los años.

Tampoco hay que olvidar el legado artístico y patrimonial que existe a través de documentos y cartografía histórica, herramientas, gastronomía, fiestas, tradiciones y costumbres (Fiestas

${ }^{6}$ En la letra de la canción Bahía de Cádiz se hace referencia a las salinas de San Fernando, Cádiz.

\footnotetext{
...Y ya estarán los esteros rezumando azul de mar. ¡Dejadme ser, salineros, granito del salinar!

¡Qué bien, a la madrugada, correr en las vagonetas llenas de nieve salada, hacia las blancas casetas!

¡Dejo de ser marinero, madre, por ser salinero!
}

Rafael Alberti, Marinero en tierra, 1925

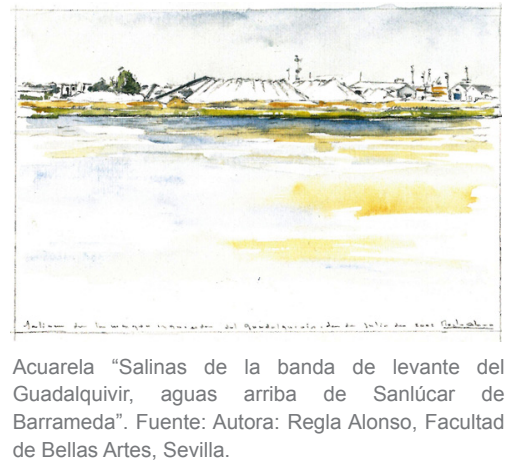




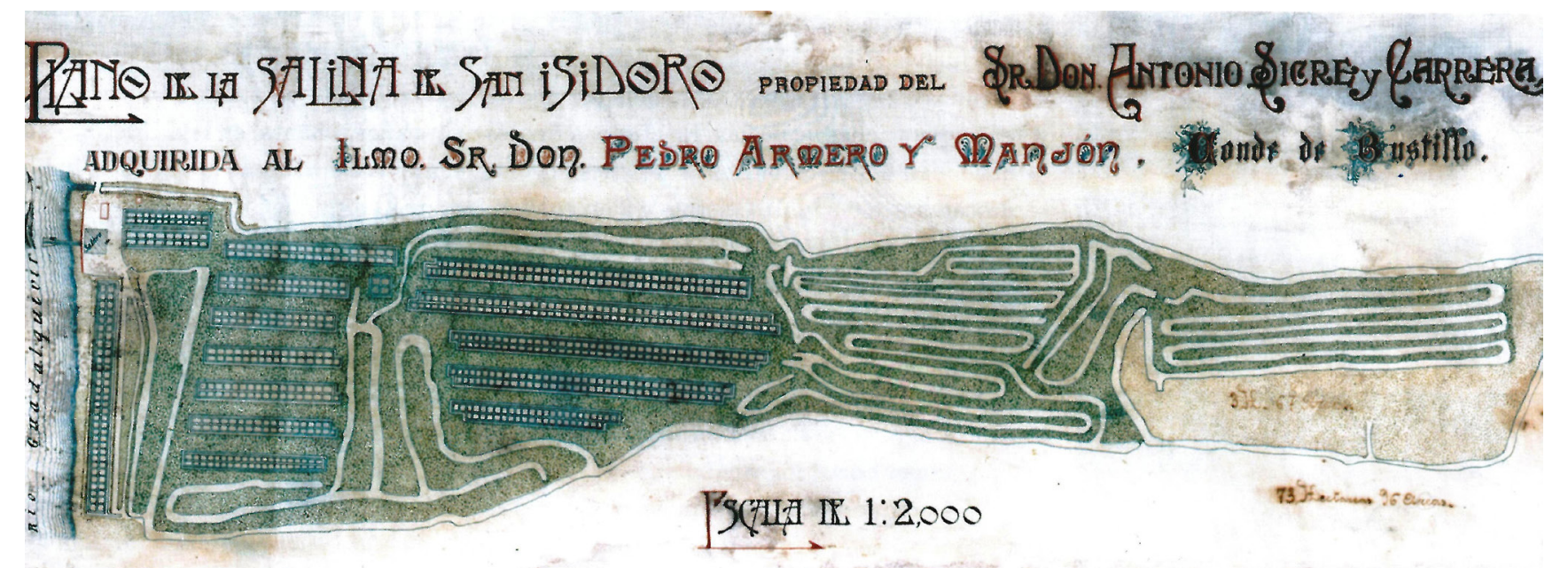

Salinas de San Isidoro a principios del s. XX, Almonte (Huelva). Fuente: Salinas de Andalucía, 2004. del Carmen y de la Sal, San Fernando, Cádiz) y el léxico específico creado para este modo de vida rural-artesanal.

En él podremos encontrar infinidad de términos salineros que varían según la provincia en la que nos encontremos: aguaje, cortá, andana, anagar, baracha, candray, empilar, forneco, madri, rabujito, etc., son algunos ejemplos de la riqueza lingüística salinera.

\section{SITUACIÓN ACTUAL DEL PATRIMONIO DE LA SAL}

A pesar del gran número de salinas, de interior y litorales, distribuidas por el territorio andaluz, hoy en su mayoría se encuentran abandonadas y en estado de ruina, olvidando la importancia cultural, histórica y económica que tuvieron en épocas pasadas.

Algunas de las causas más importantes del deterioro y desaparición del patrimonio salinero que se han detectado a lo largo de esta investigación son las siguientes:

a) La pérdida de rentabilidad de esta industria artesanal.

b) El abandono de la actividad, producido principalmente a partir de los años 60 , y el olvido social. 
c) La presión urbanística y la especulación inmobiliaria de estos últimos años (urbanizaciones, campos de golf, invernaderos, etc.), principalmente en las zonas del litoral.

d) La dificultad de accesibilidad a las salinas, principalmente en las zonas de interior.

e) El cambio de los procesos artesanales de producción por nuevas técnicas de explotación hacia la mecanización de los trabajos, que destruyen las trazas originales (proceso que también se inició en los años 60 y que continúa en hasta la actualidad).

f)Las nuevas actividades de acuicultura que aprovechan las antiguas huellas de las salinas de litoral, pero que destruyen también sus trazas originales.

g) La mayoría de las salinas son de titularidad privada, lo que dificulta la intervención de la Administración Pública para su conservación, rehabilitación o reactivación, de cara a establecer alternativas de futuro. Aunque sin embargo, la conservación de muchas de ellas es debida a la iniciativa y esfuerzo de sus pequeños propietarios.

h) La dispersión del marco normativo referente a los valores naturales y la biodiversidad, la falta de coordinación de las diferentes administraciones y la escasa presencia de figuras legales de protección sobre los elementos del patrimonio construido.

\subsection{Las salinas y el marco normativo. Figuras de protección}

Una salina es un ecosistema complejo, que depende de multitud de factores, y muy frágil frente a las amenazas externas que se pueden producir, tanto en su entorno local inmediato (presión inmobiliaria, vertido de residuos, etc.) como en el ámbito territorial más extenso y lejano (contaminación de ríos, acuíferos, fenómenos climáticos, etc.) A pesar de la complejidad competencial y la compartimentación sectorial legislativa, se han estudiado las principales figuras de protección que afectan al paisaje salinero, a través del análisis de diferentes instrumentos normativos y ámbitos territoriales, desde la escala internacional y europea, la nacional y autonómica hasta la local, incluyéndose tanto documentos de nivel legislativo como declarativo. El objetivo es poder obtener una visión integral de lo que está protegido y lo que se quiere proteger, es decir, "el paisaje objeto de la protección jurídicoadministrativa ha de serlo, como bien jurídico digno de protección, en todas y cada una
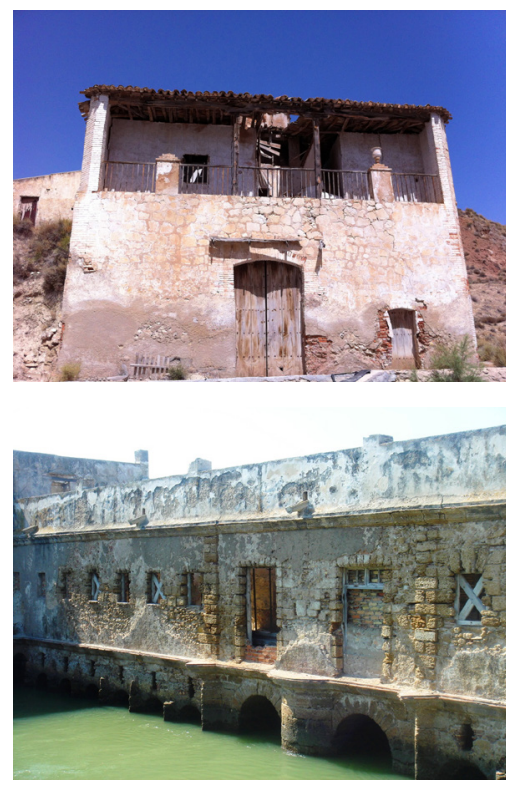

Arriba: Casa y almacén salinero. Salinas de Chillar, Hinojares (Jaén). Abajo: Molino de marea Río Amarillo, San Fernando (Cádiz). Fotografías de la autora. 


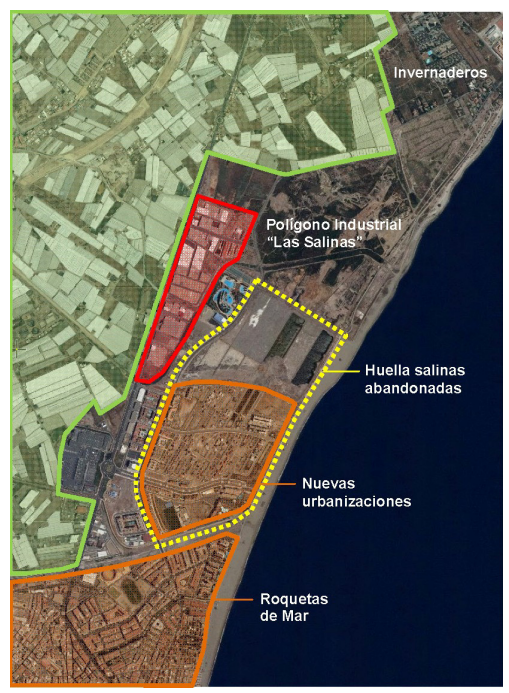

Desaparición de las salinas de San Rafael, Roquetas de Mar, Almería. Elaboración propia.

Cuadro Salinas en Reservas de la Biosfera de Andalucía. Elaboración propia. de sus dimensiones: culturales, históricas, estéticas, medio ambientales y territoriales" (Fernández, 2007:10)

Aunque tras la firma y entrada en vigor del Convenio Europeo del Paisaje, el Estado Español se comprometió a reconocer al paisaje en el ordenamiento jurídico del Estado, realmente es a través de las Comunidades Autónomas donde se realiza esta tarea. Y así lo recoge la Estrategia de Paisaje de Andalucía cuando explica el paisaje en la acción legislativa de la Junta de Andalucía: "Las competencias legislativas asumidas en relación con la protección y la gestión ambiental, la preservación del patrimonio histórico, la ordenación del territorio y el urbanismo, la agricultura y el desarrollo rural, las políticas forestales, las infraestructuras de transportes o el turismo, entre otras materias, involucran de manera directa a las Comunidades Autónomas en el reconocimiento jurídico del paisaje..." (EPA, 2012:39). Se ha podido comprobar que existen salinas con grandes valores naturales e importante biodiversidad, ya que muchas de ellas están incluidas en importantes redes ecológicas internacionales. Por ejemplo, en Andalucía se encuentran 9 Reservas de la Biosfera, de las cuales hay varias que contienen salinas en su interior?

\begin{tabular}{|c|c|c|c|}
\hline Provincia & Lugar & Año & Salinas incluidas en Reserva de la Biosfera \\
\hline Almería & Cabo de Gata-Níjar & 1997 & Salinas de Cabo de Gata \\
\hline Huelva & Marismas del Odiel & 1983 & $\begin{array}{l}\text { Salinas de Aragonesas, Salinas de Bacuta, Salinas de Caño Tendal, } \\
\text { Salinas de EI Astur } 1 \text { y Salinas de EI Astur } 2^{9}\end{array}$ \\
\hline $\begin{array}{c}\text { Huelva/Sevilla/ } \\
\text { Cádiz }\end{array}$ & Doñana & 1980 & $\begin{array}{l}\text { Cádiz: Salina de Nuestra Señora del Rocío (o de Bonanza), Salina de } \\
\text { Monte Algaida } \\
\text { Huelva: S. de San Isidoro, S. de San Diego y S. de San Rafael }\end{array}$ \\
\hline Jaén & $\begin{array}{l}\text { Sierra de Cazorla, } \\
\text { Segura y Las Villas }\end{array}$ & 1983 & Salinas de Mesto y Salinas de Chíllar \\
\hline
\end{tabular}

También hay declarados en Andalucía 6 bienes Patrimonio de la Humanidad, siendo la segunda Comunidad Autónoma, junto a Cataluña, con más bienes declarados en España. Uno de ellos es el Parque Nacional de Doñana, incluido dentro de la tipología de "patrimonio natural". Las justificaciones para su declaración, entre otras, fueron la singularidad de especies y biotopos existentes, únicos en Europa. Algunos de los más importantes son los humedales y las marismas (entre ellos los de Algaida y Bonanza, que contienen salinas), principales atractores de las aves migratorias y otras especies animales de interés.

7 Información obtenida de la página web oficial de La Consejería de Agricultura, Pesca y Medio Ambiente, Junta de Andalucía: http://www.juntadeandalucia.es [Fecha de consulta: 16 de noviembre de 2012]. 


\begin{tabular}{|c|c|c|c|}
\hline Provincia & $\begin{array}{c}\text { Bien Patrimonio de la } \\
\text { Humanidad }\end{array}$ & $\begin{array}{l}\text { Fecha de } \\
\text { inclusión }\end{array}$ & Salinas incluidas en este ámbito \\
\hline $\begin{array}{c}\text { Huelva/Sevilla/ } \\
\text { Cádiz }\end{array}$ & $\begin{array}{l}\text { Parque Nacional de } \\
\text { Doñana / Parque } \\
\text { Natural de Doñana }\end{array}$ & 1994 / 2005 & $\begin{array}{c}\text { Cádiz: Salina de Nuestra Señora del Rocío (o de Bonanza), } \\
\text { Salina de Monte Algaida } \\
\text { Huelva: Salinas de San Isidoro, Salinas de San Diego y Salinas } \\
\text { de San Rafael }\end{array}$ \\
\hline
\end{tabular}

Por tanto, en muchos de estos lugares salineros confluyen más de un tipo de categoría o figura de protección, principalmente del medio natural y la biodiversidad. Es el caso del Parque Nacional de Doñana, donde existen varias salinas, que es Patrimonio de la Humanidad (1994, UNESCO), Reserva de la Biosfera (1980) y Sitio RAMSAR (1982). Desde 1995 está reconocido, por el Consejo de Europa, con el Diploma Europeo de áreas protegidas. Además es Lugar de Importancia Comunitaria y Zona de Especial Protección para las Aves y, en consecuencia, Espacio Protegido Red Natura 2000.

A lo largo de esta investigación se ha podido comprobar que las salinas andaluzas del litoral gozan de mayor protección que las de interior, tanto en número de casos como en la variedad de aspectos protegidos. En las salinas del litoral se protegen en mayor medida los valores naturales y en las salinas de interior los valores relacionados con el patrimonio cultural. Cabe destacar que las figuras de protección más abundantes en ambos casos son las de ámbito autonómico, aunque también existen protecciones de ámbito internacional muy importantes. Sin embargo, a pesar de todo este amplio marco normativo, tanto en lo referente a los valores naturales como culturales, la mayoría de ellas están inactivas y en un estado de deterioro y desaparición muy avanzado. Como ya anunciaba en su introducción el Plan Nacional de Paisaje Cultural (2004:4): "En los Paisajes Protegidos, el medio natural, la conservación de la biodiversidad y la integridad del ecosistema constituyen los énfasis principales, mientras que en los Paisajes Culturales del Patrimonio Mundial el acento se pone en la historia humana, en la continuidad de las tradiciones culturales, y en las aspiraciones y valores sociales." En los paisajes de la sal existe una combinación de ambos aspectos, que hace especialmente compleja su gestión y protección.

También se han encontrado casos, en el ámbito municipal, en los que los desarrollos urbanísticos de tipo turístico han primado sobre los valores ecológicos y ambientales de los humedales salinos. Esta presión inmobiliaria se ha intensificado principalmente en las zonas costeras: "La política ambiental en su aplicación costera se ha desarrollado en constante lucha con la urbanística. El resultado es un territorio de contrastes a veces insostenibles,
Salinas andaluzas incluidas en bienes Patrimonio de la Humanidad. Elaboración propia. 
donde espacios de indudable valor y fragilidad o ecosistemas radicalmente vinculados a su entorno, coexisten casi sin solución de continuidad con usos urbanos en constante expansión. Esta es la realidad en la que tiene que intervenir la ordenación del territorio" (Barragán, 2004:256). La consecuencia de este "dinamismo económico" ha propiciado los casos más significativos de destrucción total de salinas, como por ejemplo: las Salinas de San Rafael, en Roquetas de Mar (Almería), las Salinas de Guardias Viejas, en El Ejido (Almería), las Salinas de Terreros, en Pulpí (Almería), las Salinas de la Desembocadura del río Guadiaro, en San Roque (Cádiz), las Salinas de la Desembocadura del río Palmones, en Algeciras (Cádiz), etc. Todos ellos debido a operaciones especulativas en el litoral andaluz, estando, las que aún se conservan, sometidas a grandes presiones urbanísticas, y que además se verán gravemente perjudicadas con la nueva Ley de Costas.

Las salinas de interior también han sufrido abandono y degradación, pero todavía conservan sus características básicas, como la estructura de las eras y balsas de evaporación, los almacenes o los edificios relacionados con la actividad salinera, ya que estos lugares han estado menos expuestos a la especulación inmobiliaria, al estar en su mayoría ubicados en áreas rurales. A pesar de ello también hay casos de destrucción, principalmente, relacionados con salinas ubicadas en terrenos susceptibles de ser urbanizados, como los próximos a los núcleos urbanos o incluso en su interior. Es el caso de salinas de La Malahá, en Granada, donde se demolieron los edificios destinados a almacenes de sal para hacer una promoción de viviendas unifamiliares con "vistas" a las salinas.

En definitiva, se puede afirmar que el paisaje salinero es una realidad dinámica, compleja y, como se ha podido apreciar, de difícil gestión. En ella confluyen características y componentes tanto naturales como culturales, materiales e inmateriales, tangibles e intangibles, y de ahí surge la necesidad de una herramienta integradora y eficaz que contemple todos estos aspectos, ya que, como se ha demostrado, la visión sectorial y la pluralidad de enfoques y de disciplinas, plasmadas en políticas, planes, programas e intervenciones en las diferentes escalas, no está siendo eficaz para detener la destrucción y desaparición de este patrimonio. 


\section{CONCLUSIONES}

Las salinas representan uno de los más claros ejemplos de sostenibilidad y adaptación al territorio que existen en Andalucía, pues usan recursos naturales para la actividad industrial y para sus sistemas constructivos (agua, piedra, madera, barro, etc.) y se adaptan perfectamente a los ciclos estacionales, al utilizar energías renovables para la producción de sal (radiación solar y viento). Estos paisajes culturales son "una síntesis del territorio basada en la vida y el trabajo acumulado sobre un espacio (en sus diferentes aspectos: histórico, antropológico y geográfico)" (Prada, 2010). Los hábitos laborales de estos paisajes de explotación, las construcciones anejas, sus medios de producción, las técnicas de almacenamiento y, en definitiva, el sistema económico generado en torno a ellos, han dejado diseminados por el territorio magníficos ejemplos de patrimonio tangible e intangible, estableciendo relaciones con las poblaciones a las que históricamente han servido, a través de carreteras, caminos y vías pecuarias, y propiciando un activo desarrollo en épocas pasadas (hasta la primera mitad del s. XX).

La recuperación de este modelo de organización territorial podría ser un sistema viable para la conservación, consolidación y gestión de este patrimonio deteriorado y olvidado: "Recuperar el sentido semántico del patrimonio como herencia, como legado de cultura y de vida que recibimos y debemos transmitir en condiciones aceptables, renueva y fortalece su significado en el debate de la sostenibilidad" (Mata, 2010:39). Para evitar su progresiva desaparición es urgente la apreciación y el reconocimiento de estos entornos culturales como patrimonio común y de aprovechamiento social inmediato, de gran valor ambiental y arquitectónico, y de que sean objeto de una gestión específica, potenciando los casos más significativos como ejemplares y valiosos recursos paisajísticos. "La apuesta por revalorizar los recursos patrimoniales propios puede suponer un modelo económicamente más viable, ambientalmente más sostenible y atento a la identidad de cada territorio y socialmente más justo" (Sabaté, 2004:8) y, por tanto, las alternativas de futuro requieren de un sistema viable, que optimice y aproveche la importancia ecológica de los paisajes de la sal, su identidad social y memoria cultural, además de favorecer la accesibilidad de los ciudadanos y su implicación en la creación y mantenimiento de esta red de itinerarios culturales a través de la participación en todos los procesos. 


\section{BIBLIOGRAFÍA}

BARRAGÁN MUÑOZ, J.M y MACÍAS BEDOYA, A. (2004). Las salinas andaluzas en la planificación y gestión integradas de las áreas litorales, en A. Pérez Hurtado de Mendoza, Salinas de Andalucía (256). Sevilla: Consejería de Medio Ambiente, Junta de Andalucía.

CARRASCO VAYÁ, J. F. \& HUESO KORTEKAAS, K. (2008). Los paisajes ibéricos de la sal. 1. Las salinas de interior. Barcelona: Fundació Territori i Paisatge. Caixa Catalunya.

FERNÁNDEZ RODRÍGUEZ, C. (2007). La protección del paisaje. Un estudio de derecho español y comparado. Madrid: Marcial Pons

FERNÁNDEZ-BACA CASARES, R. (coord.) (2010). Paisajes y patrimonio cultural en Andalucía. Tiempo, usos e imágenes. Volumen I y II. Sevilla: Junta de Andalucía. Consejería de Cultura.

GARCÍA DE DIEGO, V. (1951). Encuestas dialectales, RDTP VII. Madrid: Espasa-Calpe.

GONZÁLEZ BERNÁLDEZ, F. (1985). Invitación a la ecología humana. La adaptación afectiva al entorno. Madrid: Tecnos SA.

LUENGO, A. \& MARÍN, C. (1994). El jardín de la sal. Santa Cruz de Tenerife: Ecotopía Ediciones Tenydea, S.L..

MAdERUELO, J. (2008). Paisaje y territorio. Pensar el Paisaje 03. Centro de Arte y Naturaleza. Madrid: Abada Editores, S.L.

MAdERUELO, J. (2010). Paisaje y patrimonio. Pensar el paisaje 05. Centro de Arte y Naturaleza. Madrid: Abada Editores, S.L..

MATA, R. La dimensión patrimonial del paisaje. (2010). En MADERUELO, J., Paisaje y Patrimonio. Madrid: ABAD editores.

MENÉNDEZ PÉREZ, E. (2008). Las rutas de la sal. A Coruña: NETBIBLO, S.L..

MORĖRE MOLINERO, N. (2007). Las salinas y la sal de interior en la historia: economía, medio ambiente y sociedad. Tomos I y II. Madrid: DIKYNSON SL.

ORTEGA VARCÁRCEL, J. (1998). El patrimonio territorial: el territorio como recurso cultural y económico. Revista Ciudades (Valladolid), 4, 33-48 
ID_INVESTIGACIONES

PÉREZ HURTADO DE MENDOZA, A. (coord.) (2004) Salinas de Andalucía. Sevilla: Junta Andalucía.

PÉREZ PLAZA, A. (2008). El Paisaje Industrial en Andalucía. Jornadas Europeas de Patrimonio. Cádiz: Junta de Andalucía. Consejería de Cultura.

PLATA MONTERO, A. (2006). El ciclo productivo de la sal y salinas reales a mediados del siglo XIX. Vitoria-Gasteiz: Diputación Foral de Álava.

PORRES MARIJUÁN, R. (2003). Sazón de manjares y desazón de contribuyentes: la sal en la Corona de Castilla en tiempos de los Austrias. Bilbao: Servicio Editorial. Universidad del País Vasco

PRADA, E. (2010). Estudios del territorio, paisaje y patrimonio. Cáceres: Foro Europeo.

PRADO ARAGONÉS, J. (1992). El léxico de las salinas de Huelva. Huelva: Colección Investigación.

RUBIO NAVAS, J. (1997). Inventario nacional de recursos minerales de cloruro sódico y sales potásicas. Madrid: Insituto Tecnológico Geominero de España.

SABATÉ BEL, J. (2004) Paisajes culturales. El Patrimonio como recuro básico para un nuevo modelo de desarrollo. Revista Urban nº 9. Madrid: DUyOT, ETSAM, UPM.

SAUER, C.O. (1925). La morfología del paisaje. California: University of California Publications in Geography. Vol. 2, nº 2. Traducción de Guillermo Castro H.

TEXTOS NORMATIVOS/DECLARATIVOS (Por ámbito competencial y orden cronológico)

\section{ÁMBITO MUNDIAL}

Conferencia General de la UNESCO, 1962. Actas de la $12^{\mathrm{a}}$ reunión celebrada en París.

Humedales RAMSAR, 1971. Convención Relativa a los Humedales de Importancia Internacional especialmente como Hábitat de Aves Acuática

Reserva de la Biosfera, 1971. Programa "Man and Biosphere, MaB", UNESCO

Convención del Patrimonio Mundial, Cultural y Natural, 1972. UNESCO

\section{ÁMBITO EUROPEO}

Carta del paisaje Mediterráneo, 1992. Congreso de Poderes Locales y Regionales de Europa.

Directiva Habitats. Directiva 92/43/CEE del Consejo, de 21 de mayo de 1992, relativa a la conservación 
de los hábitats naturales y de la fauna y flora silvestres.

Estrategia Territorial Europea (ETE), hacia un desarrollo equilibrado y sostenible del territorio de la Unión Europea, 1999

Convenio Europeo del Paisaje, de 20 de octubre de 2000, del Consejo de Europa (Florencia)

Convenio de Faro. Convenio marco del Consejo de Europa, de 27 de octubre de 2005, sobre el valor del patrimonio cultural para la sociedad.

Declaración de Lisboa sobre "Redes para el desarrollo territorial sostenible del continente europeo: puentes a través de Europa", 2006

\section{ÁMBITO ESTATAL}

Ley 16/1985, de 25 de junio, del Patrimonio Histórico Español

Ley 22/1988, de 28 de julio, de Costas.

Plan Nacional de Patrimonio Industrial, 2001. Instituto del Patrimonio Cultural de España, Ministerio de Educación, Cultura y Deporte.

Plan Nacional del Paisaje Cultural, 2002. Instituto del Patrimonio Cultural de España, Ministerio de Educación, Cultura y Deporte.

Ley 42/2007, de 13 de diciembre, del Patrimonio Natural y de la Biodiversidad.

Ley 45/2007, de 13 de diciembre, para el Desarrollo Sostenible del Medio Rural.

\section{ÁMBITO AUTONÓMICO}

Resolución de 4/11/2002, de la Dirección General de la Red de Espacios Naturales Protegidos y Servicios Ambientales, por la que se aprueba el Plan Andaluz de Humedales.

Decreto 95/2003, de 8 de abril, por el que se regula la Red de Espacios Naturales Protegidos de Andalucía y su Registro.

Plan de Ordenación del Territorio de Andalucía. Decreto 236/2006, de 28 de noviembre de 2006.

Ley 14/2007, de 26 de noviembre, del Patrimonio Histórico de Andalucía

Estrategia de Paisaje de Andalucía. (2012). Sevilla: Junta de Andalucía. 


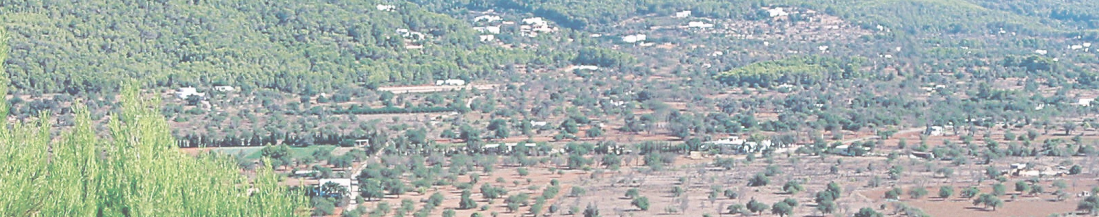

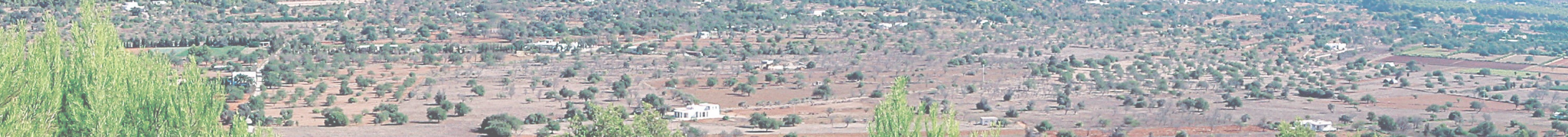

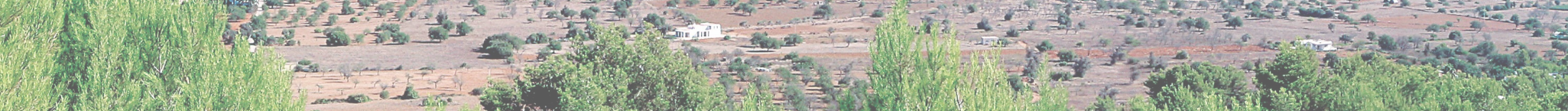

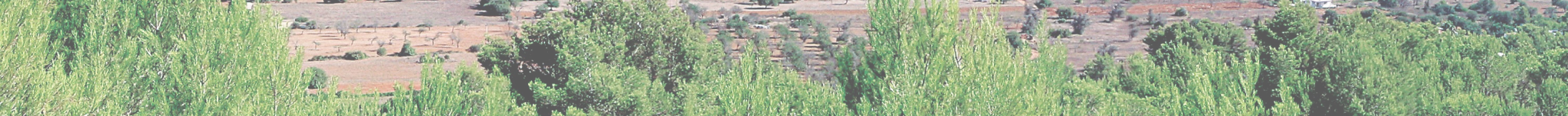

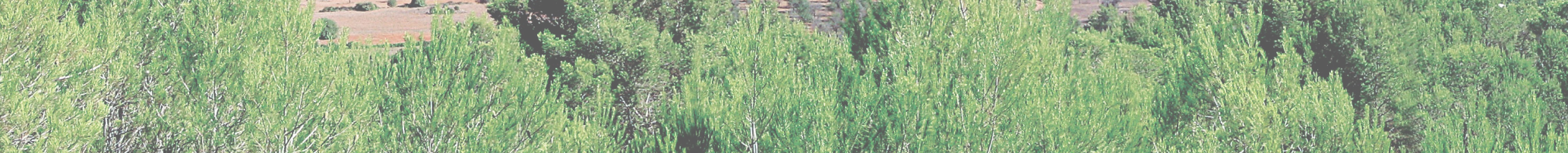

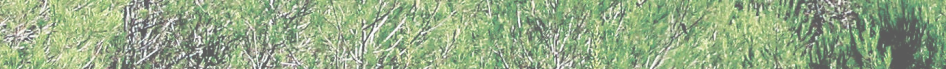

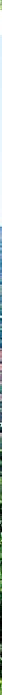

